05

\title{
Разрушение алюминиевой оболочки толстостенного составного цилиндра с помощью электрического взрыва проводника
}

\author{
(C) В.А. Морозов, ${ }^{1}$ В.М. Кац, ${ }^{1}$ Г.Г. Савенков ${ }^{2,3}$ \\ ${ }^{1}$ Санкт-Петербургский государственный университет, \\ 199034 Санкт-Петербург, Россия \\ ${ }^{2}$ Санкт-Петербургский государственный технологический институт (технический университет), \\ 190013 Санкт-Петербург, Россия \\ ${ }^{3}$ Физико-технический институт им. А.Ф. Иофрфе РАН, \\ 194021 Санкт-Петербург, Россия \\ e-mail: v.morozov@spbu.ru
}

Поступило в Редакцию 2 февраля 2021 г.

В окончательной редакции 15 марта 2021 г.

Принято к публикации 18 марта 2021 г.

Представлены результаты экспериментального исследования разрушения алюминиевой оболочки, внутрь которой запрессован цилиндр из полиметилметакрилата (ПММА). Вдоль оси цилиндра вставляется взрываемый медный проводник, к которому подведено напряжение от заряженного конденсатора 20-22kV. Давление от взрываемого проводника передается ударной волной в материал из ПММА и далее в алюминиевую оболочку. В результате происходит разрушение цилиндра из ПММА и разрыв алюминиевой оболочки. Проведена оценка амплитуды давления, создаваемого взрываемым проводником и переданного в цилиндр из ПММА и из ПММА в оболочку на основе измеренных радиальных давлений, а также напряжения разрыва оболочки. С помощью растрового микроскопа „Теscan“ и светового стереомикроскопа „Discovery“ проведено микроструктурное исследование разрушенного алюминиевого образца.

Ключевые слова: электрический взрыв проводника, ударная волна, радиальное давление, разрушение.

DOI: $10.21883 /$ JTF.2021.08.51095.24-21

\section{Введение}

Задача о нагружении толстостенных сосудов внутренним давлением в статическом случае является классической для механики деформируемого твердого тела и рассматривалась многими исследователями, например в [1-3]. Подобные более сложные динамические задачи при сравнительно малых скоростях деформации исследовались, например, в [4] и многими другими авторами. Большой интерес представляет изучение поведения материалов и конструкций при высоких скоростях деформирования.

Динамическое поведение толстостенных конструкций, таких, как цилиндры, и тонкостенных, таких, как оболочки, имеет большое значение и является актуальным во многих важных областях их применения. Актуальными являются вопросы, связанные с изучением зависящей от времени деформации или чувствительности материала к скорости деформации, а также разрушения при высокой экстремальной нагрузке.

Как правило, при изучении процесса высокоскоростного разрушения осесимметричных оболочек их динамическое нагружение осуществляется продуктами детонации взрывчатых веществ (ВВ) (см. работу [5] и обзор в ней). Однако такой процесс нагружения является высокоопасным и требует разрешительных документов на работу с $\mathrm{BB}$, что в современных условиях резко ограничивает круг научно-исследовательских организаций, имеющих возможность проведения таких работ. Наиболее современным, высокоэкономичным, высокоэффективным и наименее изученным является процесс нагружения с помощью электрического взрыва проводников (ЭВП) [6-8]. По сравнению с классическими подходами метод ЭВП позволяет достигать больших скоростей деформации (так же как и при взрыве ВВ) исследуемых образцов и в то же время гибко регулировать параметры ударного воздействия.

Как известно, с точки зрения прочностных характеристик толстостенных цилиндров, наиболее предпочтительными являются составные цилиндры. В настоящей работе используется метод ЭВП для исследования высокоскоростного нагружения и разрушения составного образца цилиндрической формы из полиметилметакрилата (ПММА) с наружной оболочкой из алюминия. Работа является продолжением исследований, начатых нами в [7], где подробно описана экспериментальная техника по нагружению, деформированию и разрушению цилиндрических образцов из полиметилметакрилата (ПММА) и фторопласта с использованием электрического взрыва проводников. В ней обстоятельно проведен анализ распространения цилиндрической волны напряжения в образцах, который увязан с образованием и эволюцией трещин. В настоящей работе удалось измерить радиальные давления на разных радиусах цилиндрических образцов из ПММА с помощью специально разработанного и оттарированного широкополосного пьезодатчика, 
т. е. получить давление в реальных, а не относительных единицах. Данное обстоятельство позволило оценить реальное окружное разрушающее напряжение алюминиевой оболочки.

\section{1. Экспериментальная методика}

Составной цилиндр приготавливался следующим образом. В трубку из алюминия марки А6 ГОСТ110692001 с внутренним диаметром $6 \mathrm{~mm}$ и длиной $18.5 \mathrm{~mm}$ запрессовывается цилиндр из ПММА, вдоль оси которого проделан канал диаметром $1 \mathrm{~mm}$. В этот канал вставляется взрываемый медный проводник диаметром $120 \mu \mathrm{m}$. К проводнику подводится напряжение $20 \mathrm{kV}$ от заряженного конденсатора. Схема эксперимента представлена на рис. 1.

Параметры эксперимента: медная проволочка длиной $l=25 \mathrm{~mm}$, диаметром $d=120 \mu \mathrm{m}$, напряжение заряда конденсатора $U=20 \mathrm{kV}$, емкость конденсатора $C=0.5 \mu \mathrm{F}$, энергия заряда конденсатора $E=100 \mathrm{~J}$.

Давление от взрываемого проводника в воздушном канале передается ударной волной в материал из ПММА и далее в алюминиевую оболочку. В результате происходит разрушение цилиндра из ПММА и разрыв алюминиевой трубки. В процессе проведения опытов удалось разорвать алюминиевую оболочку с внешним диаметром $7 \mathrm{~mm}$ и внутренним диаметром $6 \mathrm{~mm}$. Толщина оболочки составляла $0.5 \mathrm{~mm}$.

Длительность возбуждаемого в образцах импульса радиального давления находилась в пределах 3-3.5 $\mathrm{s}$. При этом скорость деформации была $\sim 10^{5} 1 / \mathrm{s}$.

Выбранные параметры взрыва проводника и геометрия составного цилиндра позволили разрушить цилиндр и алюминиевую оболочку с образованием в оболочке единственной магистральной трещины, т.е. с окружным напряжением, близким к пороговому.

Ранее нами была проведена серия исследований разрушения образцов из различных диэлектрических материалов с помощью электрического взрыва проводника [6-8]. В ходе данных исследований нами были зарегистрированы и проанализированы временные зависимости тока и напряжения, аналогичные наблюдаемым в настоящей работе.

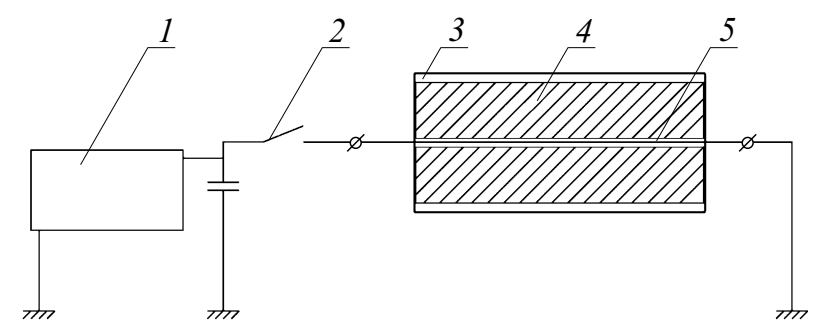

Рис. 1. Схема эксперимента: $1-$ зарядное устройство, 2 - разрядник, 3 - алюминиевая оболочка, 4 - цилиндр из ПММА, 5 - канал взрыва проводника.

\section{2. Определение давления в канале взрыва проводника, цилиндре из ПММА и алюминиевой оболочке}

Сделаем предположение, что в момент взрыва проводника радиус канала взрыва $r=0$, объем канала $V=0$. При этом плотность продуктов ЭВП по данным [9] $\rho=0.15 \cdot 10^{3} \mathrm{~kg} / \mathrm{m}^{3}$, плотность вложенной энергии $\varepsilon=13 \cdot 10^{6} \mathrm{~J}$,

$$
\frac{\rho_{0}}{\rho}=\frac{8.93 \cdot 10^{3}}{0.15 \cdot 10^{3}}=59.5
$$

Давление в воздушном канале определяем по формуле Грюнайзена

$$
P=\gamma \rho \varepsilon,
$$

где $\gamma$ - параметр Грюнайзена (для воздуха $\gamma=0.75$ ).

Далее для радиусов канала $0.2,0.4$ и $0.5 \mathrm{~mm}$ из [9] найдем значения $\rho$ и $\varepsilon$ и определим по выражению (1) давление в воздушном канале.

Полученные данные сведены в таблицу. На рис. 2 представлена зависимость давления от радиуса канала.

Передача энергии взорвавшейся проволочки в вещество окружающего ее газа в канале взрыва происходит в основном за счет образования в газе ударной волны [9]. Определим давление $P_{t 12}$ в ударной волне, прошедшей через границу между каналом взрываемого проводника и ПММА. Для этого используем соотношение из работы [10]:

$$
P_{t 12}=\frac{2 \rho_{2} c_{2}}{\rho_{2} c_{2}+\rho_{1} c_{1}} P_{i 12}
$$

где $\rho_{1}, c_{1}$ - плотность и скорость волны в канале, $\rho_{2}, c_{2}$ - плотность и скорость звука в ПММА, $P_{i 12}-$ давление в падающей волне в канале.

Давление в падающей волне в канале находим из уравнения Грюнайзена $(1)$. При этом $r=0.5 \mathrm{~mm}, \gamma=0.75$, $\rho=0.09 \mathrm{~g} / \mathrm{cm}^{3}, \varepsilon=8.5 \mathrm{~kJ}, P_{i 12}=574 \mathrm{MPa}$ (см. таблицу). Используя соотношение (2), находим радиальное давление в ПММА $P_{t 12}=1067 \mathrm{MPa}$.

С использованием специально разработанного пьезодатчика были измерены радиальные давления на разных радиусах цилиндрических образцов из ПММА. Зависимость радиального давления от радиуса цилиндра представлена на рис. 3 .

Воспользовавшись графиком зависимости радиального давления в ПММА от радиуса, находим его значение при $r=3 \mathrm{~mm}$, т.е. в падающей волне на границе ПММА-алюминиевая оболочка $P_{i 34}=970 \mathrm{MPa}$.

Далее определим радиальное давление в прошедшей ударной волне через границу ПММА-алюминиевая оболочка. Для этого воспользуемся соотношением (2)

$$
P_{t 34}=\frac{2 \rho_{4} c_{4}}{\rho_{4} c_{4}+\rho_{3} c_{3}} P_{i 34},
$$

где $\rho_{3}, c_{3}$ - плотность и скорость волны в ПММА $\left(\rho_{3}=1180 \mathrm{~kg} / \mathrm{m}^{3}, c_{3}=2670 \mathrm{~m} / \mathrm{s}\right) ; \rho_{4}, c_{4}-$ плотность 
Значения параметров взрыва проводника для различных радиусов взрывного канала

\begin{tabular}{c|c|c|c|c|c|c}
\hline $\begin{array}{c}\text { Радиус } \\
\text { взрывного канала, } \\
r, 10^{-3} \mathrm{~m}\end{array}$ & $\begin{array}{c}\text { Объем } \\
\text { вздного канала, } \\
V, 10^{-9} \mathrm{~m}^{3}\end{array}$ & $\begin{array}{c}\text { Плотность продуктов } \\
\text { испания проводника, } \\
\rho, 10^{3} \mathrm{~kg} / \mathrm{m}^{3}\end{array}$ & $\begin{array}{c}\text { Отношение } \\
\text { плотностей, } \\
\rho_{0} / \rho\end{array}$ & $\begin{array}{c}\text { Плотность } \\
\text { энергии, } \\
\varepsilon, 10^{6} \mathrm{~J} / \mathrm{kg}\end{array}$ & $\begin{array}{c}\text { Давление } \\
\text { продуктов } \\
\text { испарения, } \\
\text { эксперимент, } \\
P, 10^{9} \mathrm{~Pa}\end{array}$ & $\begin{array}{c}\text { Давление } \\
\text { продуктов } \\
\text { испарения, } \\
\text { расчет, } \\
P, 10^{9} \mathrm{~Pa}\end{array}$ \\
\hline 0 & 0 & 0.15 & 59.5 & 13.0 & 1.463 & 1.53 \\
\hline 0.2 & 3.14 & 0.12 & 74.4 & 11.5 & 1.035 & 1.07 \\
\hline 0.4 & 12.56 & 0.10 & 89.3 & 10.0 & 0.750 & 0.746 \\
\hline 0.5 & 19.625 & 0.09 & 99.2 & 8.5 & 0.574 & 0.590
\end{tabular}

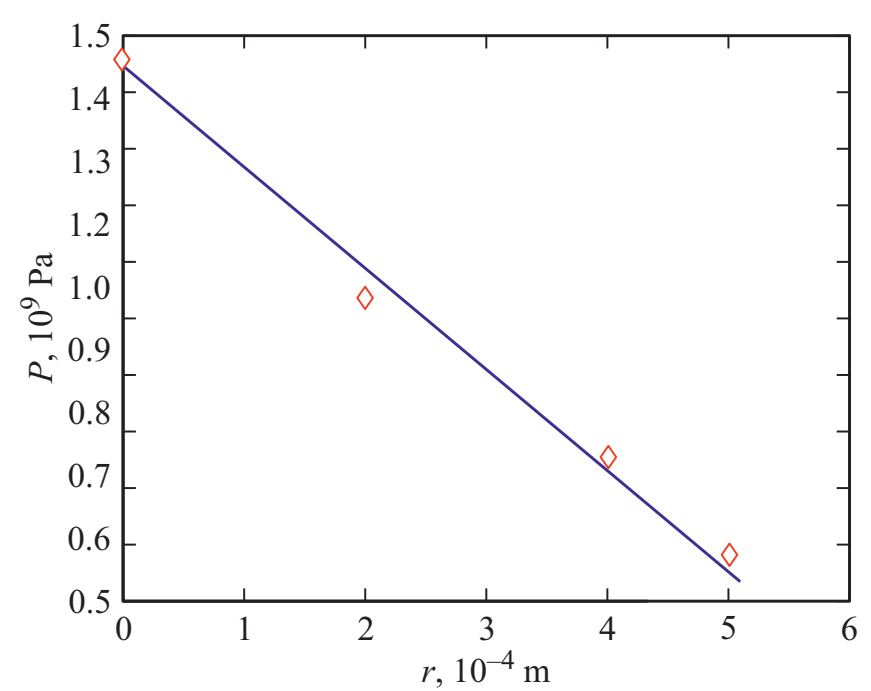

Рис. 2. Зависимость давления от радиуса канала.

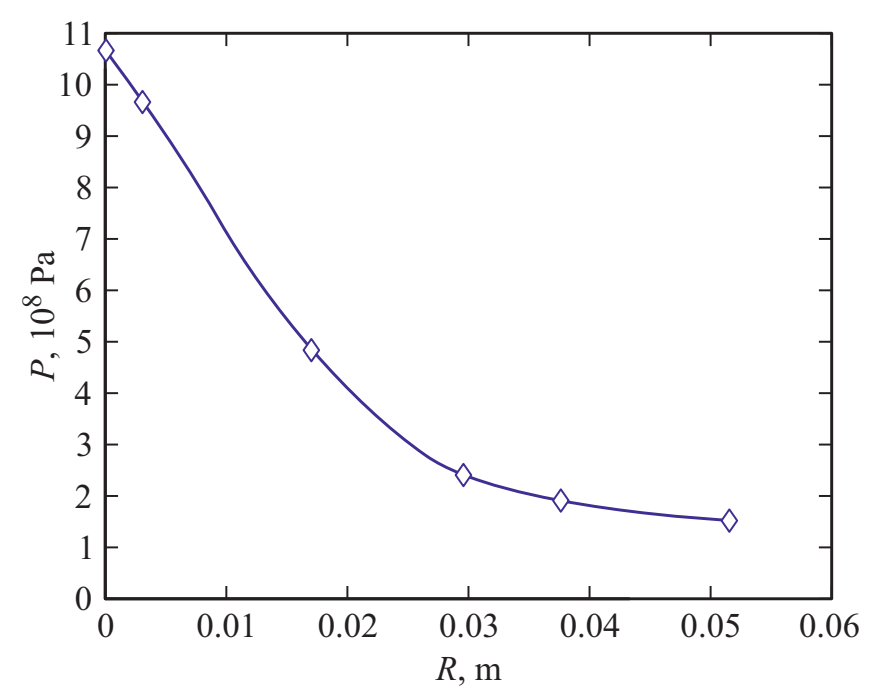

Рис. 3. Зависимость радиального давления от радиуса цилиндра. и скорость волны в алюминии $\left(\rho_{4}=2700 \mathrm{~kg} / \mathrm{m}^{3}\right.$, $\left.c_{4}=6300 \mathrm{~m} / \mathrm{s}\right)$.

В результате получаем $P_{t 34}=\sigma_{r}=1630 \mathrm{MPa}$.

Проведенный эксперимент показал, что при таком радиальном давлении произошел разрыв цилиндрической алюминиевой оболочки вдоль образующей.

Из работы [11] следует, что в толстостенных цилиндрах разница между радиальным и окружным напряжениями незначительная: $\sigma_{r} \approx 1.1 \sigma_{t}$. Отсюда $\sigma_{t} \approx \sigma_{r} / 1.1=1480 \mathrm{MPa}$. Поэтому полученный результат $\sigma_{t}=1480 \mathrm{MPa}$ можно рассматривать как напряжение разрыва алюминиевой оболочки. Он находится в согласии с данными работы [12].

Поскольку средняя скорость деформации при нагружении составного толстостенного образца составляла $\sim 10^{5} 1 / \mathrm{s}$, возник интерес к исследованию механизма разрушения в высокопластичной алюминиевой оболочке. Поэтому были проведены микроструктурные (фрактографические) исследования разрушенной оболочки. Далее приведем результаты данных исследований.

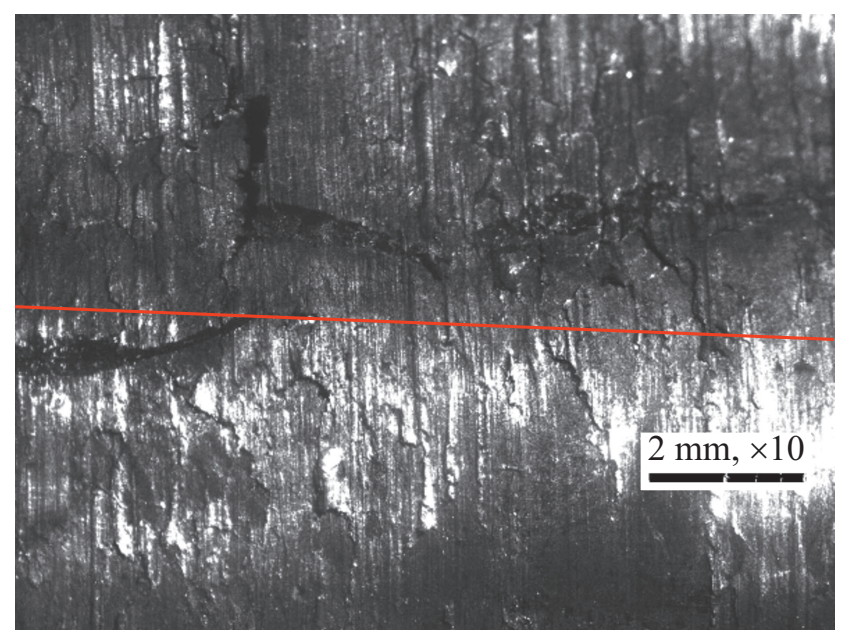

Рис. 4. Световое изображение внутренней поверхности разрушенного образца (линия изображает ось цилиндра). 

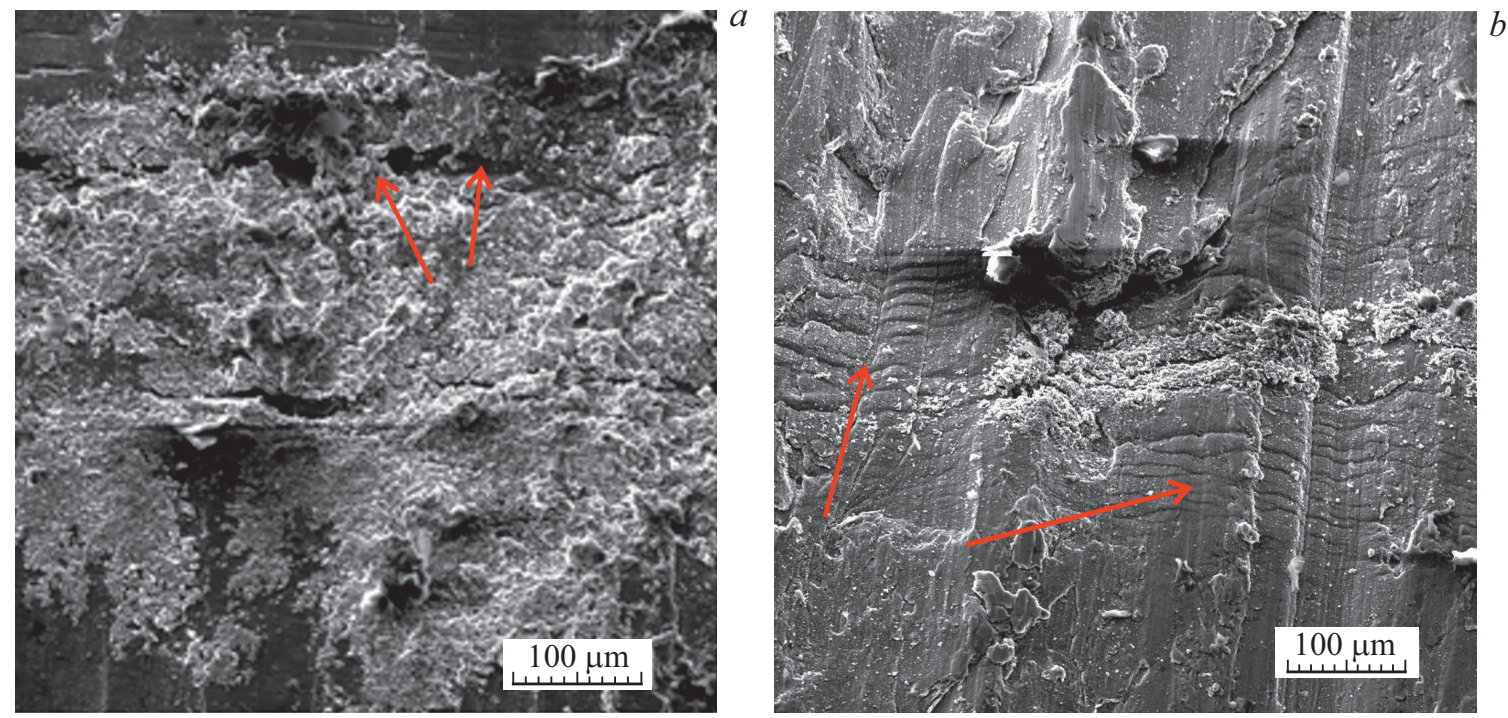

Рис. 5. Вторичные трещины разной степени раскрытия в лучах электронов (стрелками указаны округлые образования $(a)$ и следы грубого скольжения $(b)$.
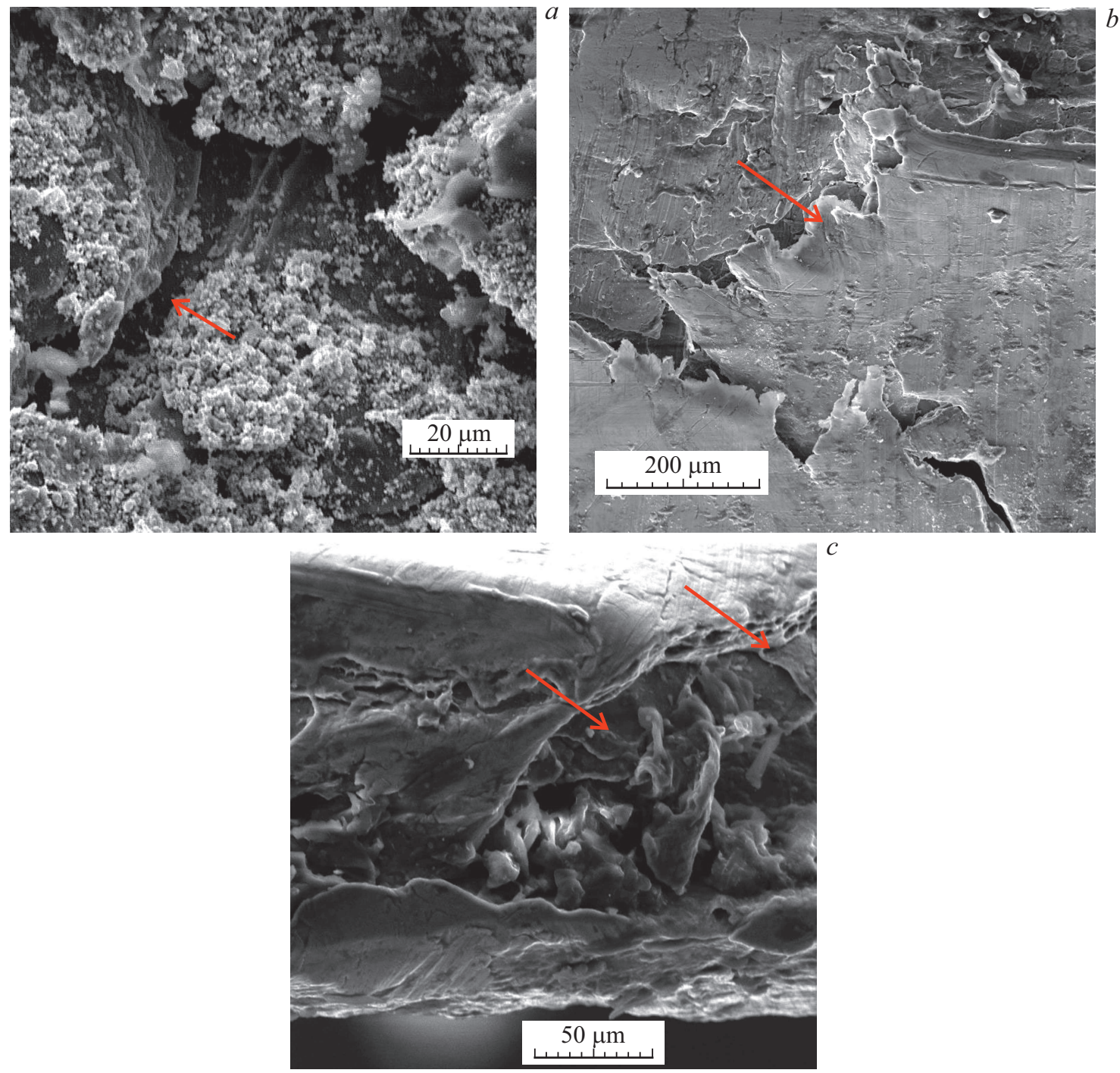

Рис. 6. Морфология раскрытых трещин на внутренней поверхности цилиндра (стрелками указаны: ступени скольжения (a); фасетки потери сдвиговой устойчивости $(b)$; ямки и расслои вязкого разрушения $(c))$. 


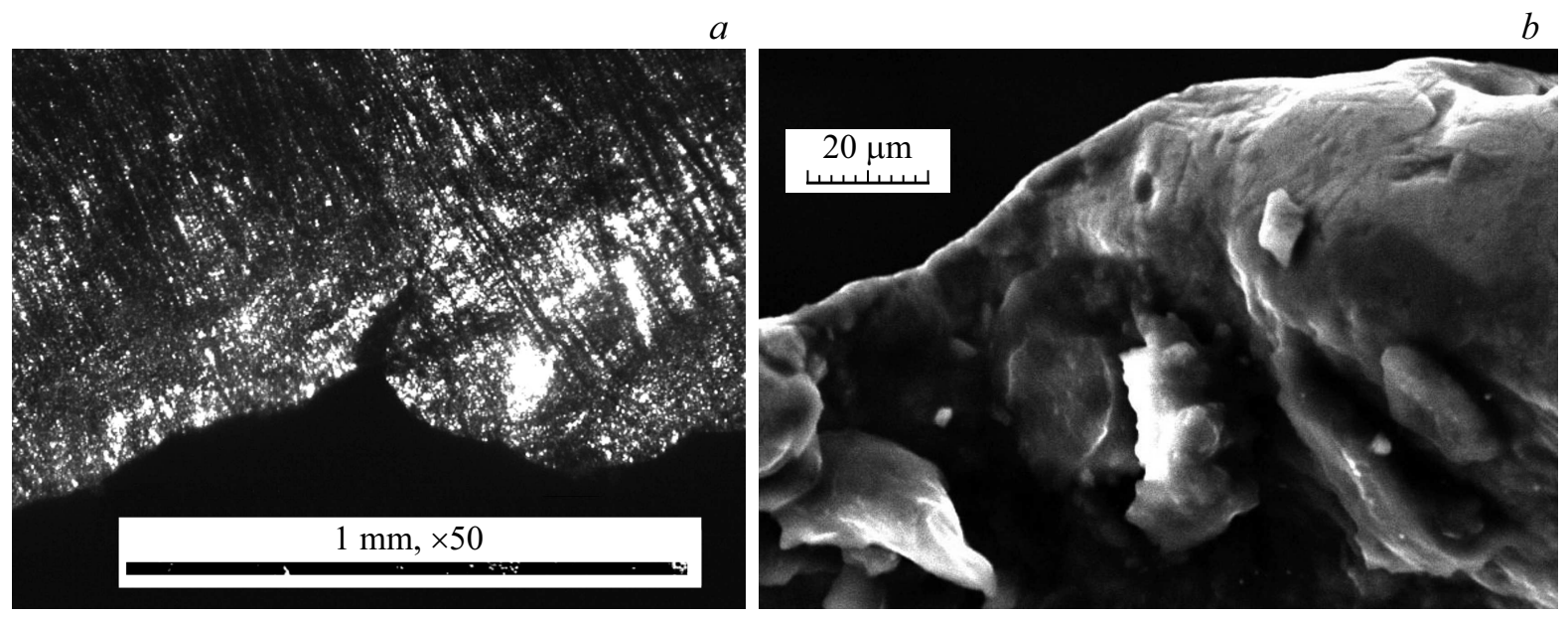

Pис. 7. Фрагменты кромок магистральной трещины в лучах света $(a)$ и электронов $(b)$.

\section{3. Результаты микроструктурных исследований разрушенного образца (исследования характера разрушения образца)}

При исследовании цилиндрического образца применялись электронный растровый микроскоп „Теscan“ и световой стереомикроскоп „Discovery“.

Визуальным осмотром установлено, что цилиндр разрушился внутренним давлением изнутри. Фронт магистральной трещины параллелен оси цилиндра (рис. 4). На внутренней поверхности присутствуют вторичные трещины, образовавшиеся при раскрытии магистральной трещины (рис. 5).

Вблизи вторичных трещин выявлены следы грубого скольжения. В глубине раскрытых дефектов замечены округлые образования ямочного микрорельефа.

При детальном электронно-микроскопическом рассмотрении берегов вторичных трещин выявлены и зафиксированы (рис. 6) следы и ступени скольжения, характерные для деформации пластичных металлов. Замечены площадки расслоения, являющиеся следами локальной потери механической устойчивости пластической деформации.

Просмотром кромок магистральной трещины установлено, что ее конфигурация представлена вязким изломом конического вида (рис. 7), типичного при разрушении пластичных металлов.

Несмотря на то что цилиндрический образец изготовлен из пластичного технически чистого алюминия марки А6 ГОСТ 11069-2001, а средняя скорость деформации составляла $\sim 10^{5} 1 / \mathrm{s}$, площадок квазихрупкого или хрупкого разрушения не выявлено.

Таким образом, на основании проведенного фрактографического анализа можно сделать вывод, что разрушение образца связано в основном с пластическими деформациями, т. е. сугубо вязкое.

\section{Заключение}

По результатам проделанных экспериментов и анализа полученных данных можно сделать следующие выводы.

1. Найдены оптимальные параметры взрываемого проводника, наполнителя и цилиндрической оболочки из алюминия для ее разрушения.

2. Полученные экспериментальные результаты по разрушению алюминиевой оболочки находятся в соответствии с известными литературными данными.

3. Микроструктурное исследование разрушения алюминиевой оболочки показало, что ее разрушение произошло давлением изнутри, о чем свидетельствует присутствие вторичных трещин на внутренней поверхности при раскрытии магистральной трещины. Фронт магистральной трещины параллелен оси цилиндра. Разрушение оболочки сугубо вязкое и связано в основном с пластическими деформациями.

\section{Конфликт интересов}

Авторы заявляют, что у них нет конфликта интересов

\section{Список литературы}

[1] Л.М. Качанов. Основы теории пластичности (Наука, M., 1969)

[2] Ю.Н. Работнов. Механика дебормируемого твердого тела (Наука, М., 1988)

[3] Л.И. Седов. Механика сплошной среды (Лань, СПб., 2004)

[4] Е.В. Ломакин. Изв. АН СССР. МТТ, 2, 168 (1968).

[5] Высокоскоростной удар. Моделирование и эксперимент / под ред. А.В. Герасимова (НТЛ, Томск, 2016)

[6] Г.Г. Савенков, В.А. Морозов, А.А. Лукин. Письма в ЖТФ, 42 (22), 23 (2016). DOI: 10.21883/pjtf.2016.22.43935.16331 [G.G. Savenkov, V.A. Morozov, A.A. Lukin. Tech. Phys. Lett., 42 (11), 1110 (2016). DOI: 10.1134/S1063785016110201] 
[7] В.А. Морозов, В.И. Богатко, С.А. Атрошенко, В.М. Кац, А.Р. Газизуллина. ЖТФ, 90 (2), 233 (2020). DOI: 10.21883/JTF.2020.02.48815.246-19 [V.A. Morozov, V.I. Bogatko, S.A. Atroshenko, V.M. Kats, A.R. Gazizullina. Tech. Phys., 65(2), 221 (2020). DOI: $10.1134 / \mathrm{S} 1063784220020152]$

[8] С.А. Атрошенко, В.А. Морозов, В.М. Кац. В сб: Физикохимические аспекты предельных состояний и структурных превращений в сплошных средах, материалах u технических системах. Bыn. 2 / под ред. чл-корр. РАН Ю.В. Петрова. (Политехника СПб., 2018), с. 58. DOI: $10.25960 / 7325-1134-5.58$

[9] А.В. Булгаков, Н.М. Булгакова, И.М. Бураков, Н.Ю. Быков, А.Н. Волков, Б.Дж. Гаррисон, К. Гурье, Л.В. Жигилей, Д.С. Иванов, Т.Е. Итина, Н.И. Кускова, М. Кьеллберг, Е.Е.Б. Кэмпбелл, П.Р. Левашов, Э. Левегль, Ж. Лин, Г.А. Лукьянов, В. Марин, И. Озеров, А.Е. Перекос, М.Е. Поварницын, А.Д. Рудь, В.С. Седой, К. Хансен, М. Хеден, К.В. Хищенко. Синтез наноразмерных материалов при воздействии мощных потоков энергии на вещество (Институт теплофизики СО РАН, Новосибирск, 2009)

[10] М.А. Исакович. Общая акустика (Наука, М., 1973)

[11] S.M. Bagheri, J. Zamani, M.H. Ghezelayagh. Mech. Adv. Mater. Struct., 24 (1), 1537 (2017). DOI: 10.1080/15376494.2015.1095374

[12] Г.И. Канель, С.В. Разоренов, А.В. Уткин, В.Е. Фортов. Экспериментальные профили ударных волн в конденсированных веществах (Физматлит, М., 2008) 